\title{
Idiopathic pulmonary fibrosis: New insights to functional characteristics at diagnosis
}

\author{
Arturo Cortes-Telles MD ${ }^{1}$, Lutz Forkert MD FRCPC ${ }^{2}$, Denis E O'Donnell MD FRCPC ${ }^{2}$, \\ Onofre Morán-Mendoza MD MSc PhD FRCPC ${ }^{2}$
}

\begin{abstract}
A Cortes-Telles, L Forkert, DE O’Donnell, O Morán-Mendoza. Idiopathic pulmonary fibrosis: New insights to functional characteristics at diagnosis. Can Respir J 2014;21(3):e55-e60.
\end{abstract}

BACKGROUND: The lung function of patients with idiopathic pulmonary fibrosis (IPF) has not been characterized in detail.

OBJECTIVE: To characterize the heterogeneous physiological abnormalities that exist in patients with IPF during their initial clinical evaluation.

METHODS: Lung function tests from 93 patients, performed within six months of the initial diagnosis of IPF, were obtained from a referral pulmonary function laboratory at a tertiary care hospital in Canada. A restrictive pattern was defined as total lung capacity (TLC) $<95$ th percentile of predicted value. Patients with obstructive lung disease, lung cancer, emphysema and other restrictive lung diseases were excluded.

RESULTS: On diagnosis, $73 \%$ of patients with IPF had a restrictive pattern, with a mean TLC of $72 \%$ of predicted. Mean forced vital capacity (FVC) was $71 \%$ and $44 \%$ of patients had an FVC $<95$ th percentile. Mean diffusing capacity for carbon monoxide (DLCO) was $60 \%$ and DLCO/ alveolar volume (VA) $92 \%$ of predicted. Increased severity of restriction - based on TLC - was associated with lower DLCO (74\% of predicted in mild restriction and $39 \%$ of predicted in severe restriction) and higher forced expiratory volume in $1 \mathrm{~s}\left(\mathrm{FEV}_{1}\right) / \mathrm{FVC}$ ratio $(82 \%$ of predicted in mild restriction and $90 \%$ of predicted in severe restriction) but not with age ( 76 years in mild restriction and 69 years in severe restriction). Regardless of severity of restriction, the average DLCO/VA ( $\geq 86 \%$ of predicted) remained within normal limits.

CONCLUSIONS: One in four patients with IPF had normal TLC and more than one-half had a normal FVC during initial evaluation. As the severity of the restriction increased, $\mathrm{FEV}_{1} / \mathrm{FVC}$ increased, DLCO decreased but DLCO/VA remained normal.

Key Words: Idiopathic pulmonary fibrosis; Lung function; Restrictive disease

Tnterstitial lung diseases (ILDs) are a heterogeneous group of illnesses that share common clinical, radiological and physiological patterns but varying pathological appearances (1). They also differ in their prognosis and response to treatment $(2,3)$. Idiopathic pulmonary fibrosis (IPF) is the most common and the most severe ILD of unknown cause, with a reported median survival of three to five years (4). Several studies have reported that the decline in lung function is a useful predictor of mortality in patients with IPF, particularly the decline in forced vital capacity (FVC) $(5,6)$, total lung capacity (TLC) (5), alveolar-arterial (A-a) gradient (2) and diffusing capacity for carbon monoxide (DLCO) $(2,7,8)$. Most of the descriptions of lung function in patients with IPF are from therapeutic trials (9-13) or from studies aimed at identifying prognostic factors of survival (2,14-17). Given the known, nonuniform distribution of pathological change within the lungs of patients with IPF, it is reasonable to assume that the nature and extent of pulmonary function abnormalities would be variable. Moreover, assessment of physiological impairment may be further confounded by factors such as smoking history and obesity. In fact, previous studies and clinical experience indicate broad physiological diversity of mechanical volume restriction and pulmonary gas

\author{
La fibrose pulmonaire idiopathique : un nouvel éclairage \\ sur les caractéristiques fonctionnelles au diagnostic
}

HISTORIQUE : La fonction pulmonaire des patients atteints de fibrose pulmonaire idiopathique (FPI) n'est pas caractérisée en détail.

OBJECTIF : Caractériser les anomalies physiologiques hétérogènes présentes chez les patients atteints de FPI lors de leur évaluation clinique initiale. MÉTHODOLOGIE : Les chercheurs ont obtenu les explorations fonctionnelles respiratoires de 93 patients, effectuées dans les six mois suivant leur diagnostic initial de FPI, auprès du laboratoire d'aiguillage de la fonction respiratoire d'un hôpital de soins tertiaires du Canada. Un profil restrictif était défini par une capacité pulmonaire totale (CPT) inférieure au $95^{\mathrm{e}}$ percentile de la valeur prévue. Les patients atteints de maladie pulmonaire obstructive, de cancer du poumon, d'emphysème et d'autres syndromes respiratoires restrictifs étaient exclus de l'étude.

RÉSULTATS : Au diagnostic, $73 \%$ des patients atteints de FPI présentaient un profil restrictif, pour une CPT moyenne de $72 \%$ de celle prévue. Leur capacité vitale forcée $(\mathrm{CVF})$ s'élevait à $71 \%$, et $44 \%$ des patients présentaient une CVF inférieure au $95^{\mathrm{e}}$ percentile. Leur capacité de diffusion du monoxyde de carbone $\left(C D^{\mathrm{MC}}\right)$ moyenne s'élevait à $60 \%$ et le ratio $C D^{\mathrm{MC}}$ volume alvéolaire (VA) à $92 \%$ de la valeur prévue. Une restriction plus grave, d'après la $\mathrm{CPT}$, s'associait à une $\mathrm{CD}^{\mathrm{MC}}$ plus faible $(74 \%$ de la valeur prévue en cas de restriction bénigne et $39 \%$ de la valeur prévue en cas de restriction grave) et à un ratio volume expiratoire maximal par seconde (VEMS)/CVF plus élevé ( $82 \%$ de la valeur prévue en cas de restriction bénigne et $90 \%$ de la valeur prévue en cas de restriction grave), mais pas à l'âge (76 ans en cas de restriction bénigne et 69 ans en cas de restriction grave). Quelle que soit la gravité de la restriction, le ratio $\mathrm{CD}^{\mathrm{MC}} / \mathrm{VA}$ moyen (au moins $86 \%$ de la valeur prévue) se maintenait dans les limites normales. CONCLUSIONS : Un patient atteint de FPI sur quatre présentait une CPT normale, et plus de la moitié, une CVF normale lors de l'évaluation initiale. À mesure que la gravité de la restriction augmentait, le ratio $\mathrm{FEV}_{1} / \mathrm{CVF}$ augmentait et la $\mathrm{CD}^{\mathrm{MC}}$ diminuait, tandis que le ratio $\mathrm{CD}^{\mathrm{MC}} / \mathrm{VA}$ demeurait normal.

exchange abnormalities in IPF (2,14-17). To obtain new knowledge on the physiological abnormalities of IPF, we conducted a retrospective analysis of lung function data from a sizable group of patients with a confirmed diagnosis of IPF. Therefore, the purpose of the current study was to provide a comprehensive characterization of the physiological abnormalities that were present in patients with IPF around the time of diagnosis and to undertake cross-sectional comparisons of these physiological abnormalities in subgroups stratified according to severity of lung volume restriction, accounting for effects of obesity and chronic obstructive pulmonary disease.

\section{Study design}

\section{METHODS}

The present study was a retrospective analysis of patients diagnosed with IPF at Kingston General Hospital (KGH, Kingston, Ontario) between January 1, 1997 and October 31, 2011. The respirology clinics at $\mathrm{KGH}$ serve as a tertiary care, diagnostic referral centre for family physicians in Kingston and the communities of southeastern Ontario, with an estimated catchment population of approximately 600,000. All respirologists serving this area during the study period were located

${ }^{1}$ Department of Respiratory Physiology, National Institute of Respiratory Diseases, Mexico City, Mexico; ${ }^{2}$ Division of Respiratory and Critical Care Medicine, Kingston General Hospital and Queen's University, Kingston, Ontario

Correspondence: Dr Onofre Morán-Mendoza, Division of Respirology and Critical Care Medicine, Queen's University, 102 Stuart Street, Kingston, Ontario K7L 2V6. Telephone 613-548-1380, fax 613-549-1459, e-mail morano@queensu.ca 


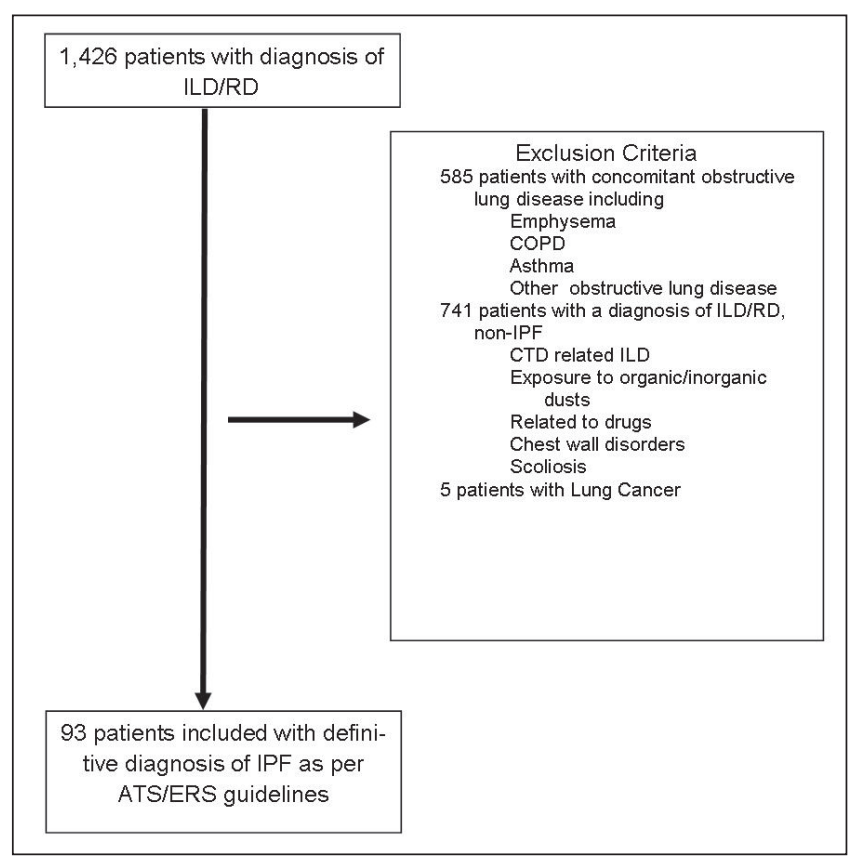

Figure 1) Selection flow chart of study subjects. ATS American Thoracic Society; COPD Chronic obstructive pulmonary disease; CTD Connective tissue disease; ERS European Respiratory Society; ILD Interstitial lung disease; IPF Idiopathic pulmonary fibrosis; RD Restrictive disease on pulmonary function tests

at $\mathrm{KGH}$, and all patients with ILDs, including those with a presumptive IPF, are routinely referred to $\mathrm{KGH}$ for diagnosis and management.

\section{Selection of study subjects}

Patients with the diagnosis of IPF during the period of interest were identified from three sources: patients referred to the respirology clinics; patients admitted to $\mathrm{KGH}$; and the $\mathrm{KGH}$ pulmonary function test (PFT) laboratory database.

Patients with a diagnosis of pulmonary fibrosis and available PFT data from the main respirology clinics were selected. Their medical chart records were retrieved to confirm a definitive diagnosis of IPF. Also identified were patients with IPF from the KGH database among those with ILD according to the corresponding International Classification of Diseases, Ninth and 10th Revisons classification codes (516.3, 516.8, J84.1 and J84.9); and by independently selecting patients with the diagnosis of restriction (based on a reduced TLC from the PFT laboratory database). The two databases were then crosslinked, and patients who had a definitive diagnosis of IPF and had PFT data were selected for the study.

All patients $\geq 18$ years of age (Figure 1 ) who had a definitive diagnosis of IPF according to the American Thoracic Society (ATS)/ Eurpean Respiratory Society (ERS)/Japanese Respiratrory Society/ Asociación Latinoamericana de Tórax statement (18) were included based on the presence of a pattern compatible with usual interstitial pneumonia (UIP) on high-resolution computed tomography (HRCT) chest scan; a histopathological diagnosis of UIP on lung biopsy, if available; and exclusion of other known causes of pulmonary fibrosis on clinical and laboratorial bases and/or on bronchoscopy (eg, connective tissue disorders, drugs, domestic and occupational environmental exposures). Also excluded were patients with concomitant obstructive lung disease (forced expiratory volume in $1 \mathrm{~s}\left[\mathrm{FEV}_{1}\right] / \mathrm{FVC}$ ratio $<70 \%$ ), emphysema on chest CT (if mentioned in the radiologist's report) before or concurrent diagnosis of lung cancer, as well as patients with extrapulmonary restrictive lung diseases such as scoliosis, neuromuscular diseases and chest wall deformities.
TABLE 1

Characteristics of patients with idiopathic pulmonary fibrosis on initial diagnosis $(n=93)$

\begin{tabular}{lc}
\hline Characteristic & \\
\hline Age, years, mean $\pm \mathrm{SD}$ (minimum-maximum) & $72 \pm 10(47-92)$ \\
Male/female, $\mathrm{n} / \mathrm{n}(\% / \%)$ & $63 / 30(68 / 32)$ \\
$\mathrm{BMI}, \mathrm{kg} / \mathrm{m}^{2}$, mean $\pm \mathrm{SD}$ (minimum-maximum) & $29.2 \pm 5.1(18.6-41.2)$ \\
Normal: $18.5-24.9$ & $17(18)$ \\
Overweight: $25-29.9$ & $41(44)$ \\
Obese: $30-39.9$ & $33(36)$ \\
Morbidly obese: $\geq 40$ & $2(2)$ \\
Smoking status & \\
Ex-smoker & $48(52)$ \\
Never smoker & $30(32)$ \\
Unknown & $15(16)$ \\
Work-up diagnosis & \\
Inpatients & $16(17)$ \\
Clinical and chest HRCT & $9(56)$ \\
Chest HRCT and lung biopsy & $7(44)$ \\
Outpatients & $77(83)$ \\
Clinical and chest HRCT & $51(66)$ \\
Chest HRCT and lung biopsy & $26(34)$ \\
\hline
\end{tabular}

Data presented as $n$ (\%) unless otherwise indicated. BMI Body mass index; HRCT High-resolution computed tomography

\section{PFTs}

PFT data from all patients with a diagnosis of IPF from the KGH PFT laboratory database were retrieved using the patient's hospital registration number. This enabled a deterministic linkage because the registration number is unique for each individual in both the $\mathrm{KGH}$ and PFT laboratory databases. The initial PFTs performed within six months after the diagnosis of IPF were selected. The PFTs of patients seen in the respirology clinics are routinely performed at the $\mathrm{KGH}$ PFT laboratory (using $\mathrm{V}_{\max } 22$ [Sensormedic Equipment, USA] using the ATS/ERS criteria [19-21]). Predictive values used for spirometry were those from Crapo et al (22); for lung volumes, those from Goldman and Becklake (23); for airway resistance, those from Briscoe and Dubois (24); and for single-breath diffusing capacity and single breath diffusing capacity/alveolar volume (VA), those from Crapo and Morris (25). The study was approved by the Research Ethics Board of Queen's University (Kingston, Ontario).

\section{Statistical analysis}

Statistical measures of central tendency and dispersion were used to summarize the data. Continuous variables are presented as mean $\pm \mathrm{SD}$ (minimum and maximum [min-max]). Categorical data are presented as frequencies and percentages.

The presence of a restrictive pattern was based on a reduction in TLC below the 95th percentile of the predicted value and a normal $\mathrm{FEV}_{1} / \mathrm{FVC}$ ratio (26). Because there is no guideline defining the severity of restriction of lung function, the severity of restriction was classified according to TLC $\geq 75$ th, $\geq 50$ th, $\geq 25$ th and 10 th percentiles, which closely corresponded to the following: TLC $\geq 80 \%$ predicted (very mild restriction); $\geq 70 \%$ (mild restriction); $\geq 60 \%$ (moderate restriction); $\geq 50 \%$ (severe restriction); and $<50 \%$ of predicted (very severe restriction). The demographic, physiological and arterial blood gas $(A B G)$ characteristics of patients were then compared among the categories of severity of restriction.

One-way ANOVA was used for continuous variables, with Tukey's post hoc adjustments used for multiple comparisons. $\chi^{2}$ or Fisher's exact test were used for categorical variables. The above analyses were performed for all patients with IPF, and also after excluding obese patients (body mass index $\geq 30 \mathrm{~kg} / \mathrm{m}^{2}$ ). All analyses were performed using SPSS version 15 (IBM Corporation, USA). 
TABLE 2

Lung function* of patients with idiopathic pulmonary fibrosis during initial evaluation $(n=93)$

\begin{tabular}{|c|c|}
\hline Variable & Mean \pm SD (minimum-maximum) \\
\hline \multicolumn{2}{|l|}{ Spirometry } \\
\hline FVC & $71 \pm 18(33-130)$ \\
\hline $\mathrm{FEV}_{1}$ & $87 \pm 21(40-157)$ \\
\hline $\mathrm{FEV}_{1} / \mathrm{FVC}$ ratio & $84 \pm 6(70-98)$ \\
\hline $\mathrm{FEF}_{25-75}$ & $114 \pm 42(35-225)$ \\
\hline Peak expiratory flow & $102 \pm 22(47-146)$ \\
\hline \multicolumn{2}{|l|}{ Lung volumes } \\
\hline TLC & $72 \pm 16(37-110)$ \\
\hline Vital capacity & $73 \pm 19(33-131)$ \\
\hline Inspiratory capacity & $72 \pm 22(23-123)$ \\
\hline Functional residual capacity & $71 \pm 20(35-136)$ \\
\hline Expiratory reserve volume & $94 \pm 54(7-306)$ \\
\hline RV & $62 \pm 22(18-152)$ \\
\hline RV/TLC ratio & $36 \pm 13(15-106)$ \\
\hline Airway resistance & $123 \pm 44(38-248)$ \\
\hline Specific airway resistance & $109 \pm 45(39-317)$ \\
\hline \multicolumn{2}{|l|}{ Lung diffusion capacity } \\
\hline DLco & $60 \pm 19(30-118)$ \\
\hline DLco/VA & $92 \pm 20(48-140)$ \\
\hline \multicolumn{2}{|c|}{ Arterial blood gas analysis ${ }^{\dagger}$, absolute values } \\
\hline $\mathrm{pH}$ & $7.43 \pm 0.03(7.36-7.50)$ \\
\hline $\mathrm{PaCO}_{2}, \mathrm{mmHg}$ & $39 \pm 5(27-48)$ \\
\hline $\mathrm{PaO}_{2}, \mathrm{mmHg}$ & $69 \pm 11(51-96)$ \\
\hline $\mathrm{P}(\mathrm{A}-\mathrm{a}) \mathrm{O}_{2}$ & $31 \pm 11(3-57)$ \\
\hline Bicarbonate, $\mathrm{mmoL} / \mathrm{L}$ & $25 \pm 3(16-30)$ \\
\hline $\mathrm{SaO}_{2}, \%$ & $93 \pm 3(85-98)$ \\
\hline
\end{tabular}

*Presented as percent predicted; ${ }^{+} n=45$. Kingston Ontario's altitude is $93 \mathrm{~m}$ above sea level. DLco Diffusing capacity for carbon monoxide; DLCo/NA DLco adjusted for alveolar volume; FEF $25-75$ Forced expiratory flow at $25 \%$ to $75 \%$ of vital capacity (VC); FEV 1 Forced expiratory volume in $1 \mathrm{~s}$; FVC Forced vital capacity; $P(A-a) O_{2}$ Partial pressure of alveolar-arterial oxygen gradient; $\mathrm{PaCO}_{2}$ Partial pressure of carbon dioxide; $\mathrm{PaO}_{2}$ Partial pressure of oxygen; $R V$ Residual volume; $\mathrm{SaO}_{2}$ Saturation of arterial oxygen; TLC Total lung capacity

\section{RESULTS}

After applying the selection criteria (Figure 1) 93 patients with IPF were included the present study. Patient characterisitics are summarized in Table 1 . The mean $( \pm$ SD) age of patients on initial diagnosis was $72 \pm 10$ years and $38 \%$ were obese. The diagnosis of IPF was established in $65 \%$ of the 93 patients based on a typical UIP pattern on HRCT, and in 35\% of the patients through surgical lung biopsy. Eightythree percent of patients had respiratory symptoms (dyspnea and/or cough) and were diagnosed with IPF as outpatients. The remaining $17 \%$ were diagnosed during a hospital admission: 63\% had dyspnea or chronic cough and a chest HRCT with a UIP pattern; the remaining $37 \%$ were asymptomatic and their diagnosis was suspected on incidental findings from a chest or abdominal CT performed for another condition. Three of the 93 patients experienced an acute exacerbation and were hospitalized on initial diagnosis. All patients with incidental findings of IPF on CT underwent lung biopsy to confirm the diagnosis.

\section{Evaluation of lung function}

Among patients with IPF diagnosed as outpatients, $71 \%$ had a restrictive pattern on PFTs, compared with $81 \%$ of those diagnosed during a hospital admission $\left(\chi^{2}=0.650 ; \mathrm{P}=0.42\right)$.

Lung function data at the time of initial evaluation are shown in Table 2. The mean TLC was $72 \%$ of predicted, and $73 \%$ (68 of 93) of patients had a restrictive pattern based on TLC ( $<95 \%$ percentile). The mean FVC was $71 \%$ of predicted and $44 \%$ (41 of 93 ) of patients had a restrictive pattern based on FVC ( $<95 \%$ percentile). There were

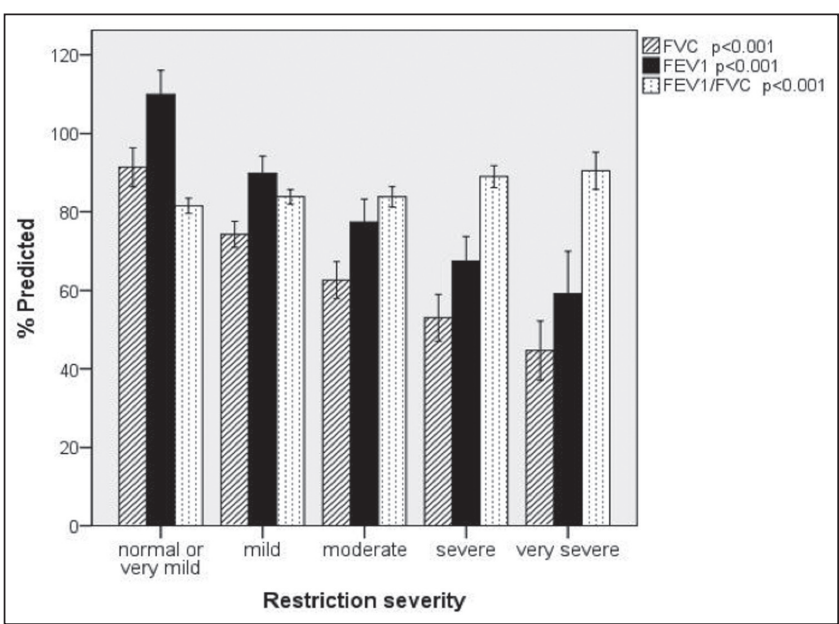

Figure 2) Mean forced vital capacity (FVC), forced expiratory volume in $1 \mathrm{~s}\left(\mathrm{FEV}_{1}\right)$ and $\mathrm{FEV}_{1} / \mathrm{FVC}$ ratio according to the severity of restriction in patients with idiopathic pulmonary fibrosis. Error bars represent 95\% CIs

$27(40 \%)$ patients with restriction - based on a low TLC - who had normal FVC, while none of the patients with low FVC $(<95 \%$ percentile) had a normal TLC. The variability of TLC as percent of predicted (min-max) was $37 \%$ to $110 \%$, which was lower than the variability of FVC (min-max) $33 \%$ to $130 \%$.

The mean DLCO was low (60\%), but the mean DLCO adjusted for VA (DLCO/VA) was within normal limits (92\%). Only 2\% of IPF patients had a high DLCO and $40 \%$ had a high DLCO/VA $(\geq 100 \%$ of predicted).

$\mathrm{ABG}$ data on room air were obtained in 45 patients during initial evaluation. The mean $\mathrm{P}(\mathrm{A}-\mathrm{a}) \mathrm{O}_{2}$ for all patients was increased $(31 \pm 11 \mathrm{mmHg})$ and the mean partial pressure of oxygen $\left(\mathrm{PaO}_{2}\right)$ was slightly low $(69 \pm 11 \mathrm{mmHg})$, as was the arterial oxygen saturation $\left(\mathrm{SaO}_{2}\right)(93 \pm 3 \%)$. The mean acid-base balance and $\mathrm{PaCO}_{2}$ were within normal limits.

Analysis based on the severity of restriction

Demographic and lung function data according to the severity of restriction are shown in Table 3. The severity of restriction was not associated with the age or sex of patients.

A lower TLC value was associated with lower FVC and forced expiratory flows but with a significantly high $\mathrm{FEV}_{1} / \mathrm{FVC}$ ratio. The mean $\mathrm{FEV}_{1} / \mathrm{FVC}$ ratio progressively increased with severity of restriction (on average, $90 \%$ in patients with severe and very severe restriction) (Figure 2). The forced expiratory flow between $25 \%$ and $75 \%$ of vital capacity and the airway resistance did not change significantly and remained either normal or above normal at all degrees of restriction.

Lower TLC values were associated with lower values of DLCO; however, regardless of the severity of restriction, the mean DLCO/VA remained within normal range (Figure 3 ).

In $\mathrm{ABG}$, the $\mathrm{PaO}_{2}$ declined as the severity of the restriction increased, and was accompanied by an increase in the $\mathrm{P}(\mathrm{A}-\mathrm{a}) \mathrm{O}_{2}$. The oxygen saturation also decreased progressively with increased severity of restriction; however, the decrease was only statistically and clinically significant $\left(\mathrm{SaO}_{2}<90 \%\right)$ in patients with very severe restriction ( TLC $<50 \%$ ), as shown in Figure 4 . There were no significant changes in the acid-base parameters.

After excluding obese patients, the evaluation of lung function and the analyses based on the severity of restriction showed minor variations in the numerical results; however, the lung function abnormalities and the patterns associated with increased severity of restriction described above remained unchanged. 
TABLE 3

Severity of restriction based on total lung capacity (TLC) categorized according to percentile and percent predicted

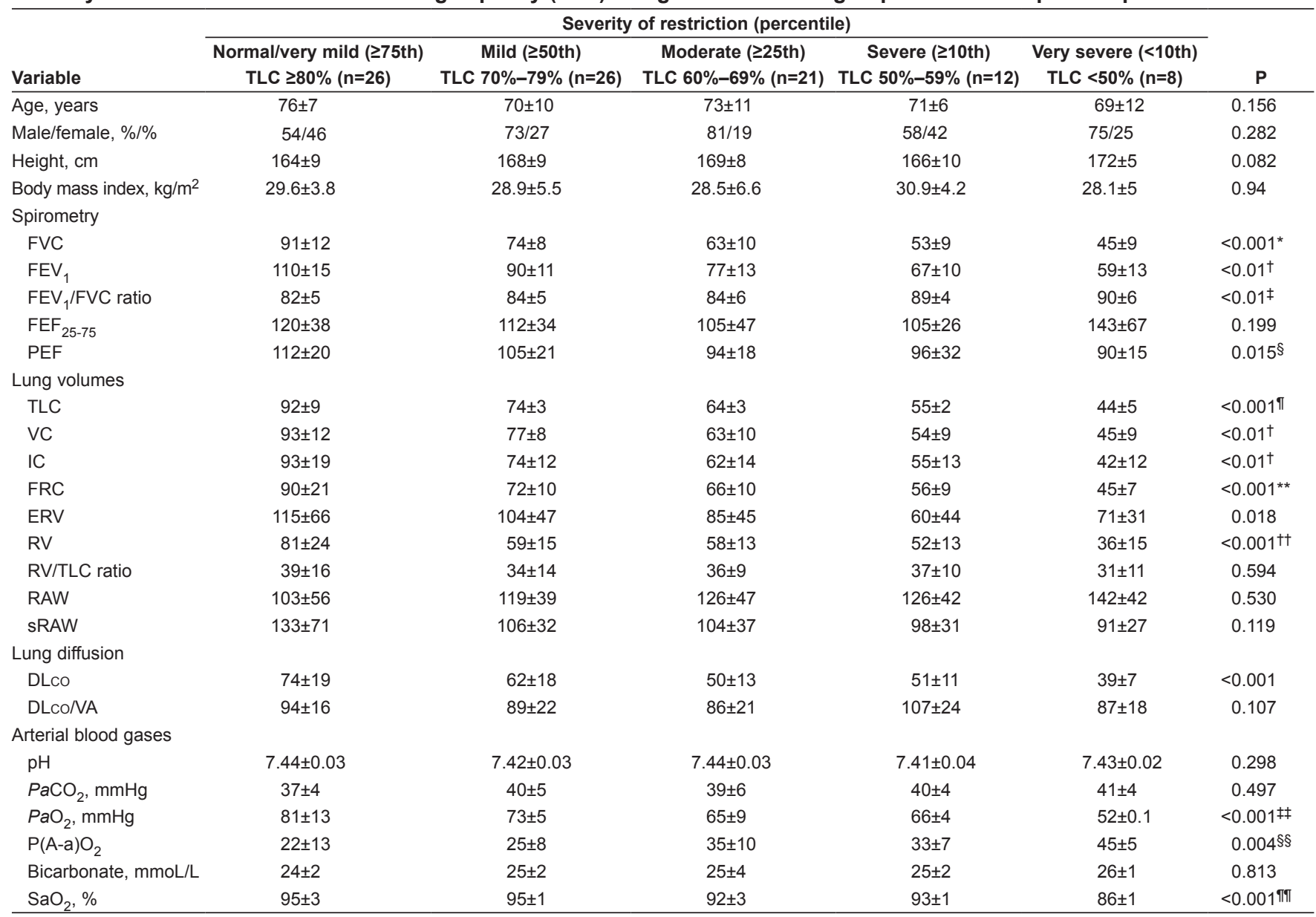

Data presented as mean $\pm S D$ unless otherwise indicated. $P$ values from ANOVA with post-hoc Tukey adjustment for multiple comparisons, except for sex, in which $\chi^{2}$ and Fisher's exact test were used. ${ }^{*} P<0.01$ for all comparisons except for severe versus very severe; ${ }^{\dagger} P<0.01$ for all comparisons except for moderate versus severe and severe versus very severe; $¥ P=0.01$ normal versus severe and very severe, $P<0.05$ mild versus severe and very severe, and moderate versus severe and very severe; $\$ P=0.03$ normal versus moderate; ${ }^{\top} P<0.0001$ for all comparisons; ${ }^{* *} P<0.001$ normal versus mild, moderate, severe and very severe, $P<0.02$ mild versus severe and very severe, and moderate versus very severe; ${ }^{\dagger \dagger} P<0.001$ normal versus mild, moderate, severe and very severe, $P=0.03$ mild versus very severe, and moderate versus very severe; $¥ ¥ P<0.002$ normal versus moderate, severe and very severe, and mild versus very severe; $\$ \S P<0.04$ normal versus moderate and very severe, and mild versus very severe; $\uparrow \uparrow<0.001$ normal, mild and moderate versus very severe, and severe versus very severe, $P=0.03$ normal versus moderate. DLco Diffusing capacity for carbon monoxide; DLco/VA DLco adjusted for alveolar volume; ERV Expiratory reserve volume; FEF $25-75$ Forced expiratory flow at $25 \%$ to $75 \%$ of vital capacity (VC); FEV 1 Forced expiratory volume in 1 s; FRC Functional residual capacity; IC Inspiratory capacity; FVC Forced vital capacity; $\mathrm{P}(\mathrm{A}-\mathrm{a}) \mathrm{O}_{2}$ Partial pressure of alveolar-arterial oxygen gradient; $\mathrm{PaCO}_{2}$ Partial pressure of carbon dioxide; $\mathrm{PaO} \mathrm{O}_{2}$ Partial pressure of oxygen; $\mathrm{PEF}$ Peak expiratory flow; RAW Airway resistance; $\mathrm{SaO}_{2}$ Oxygen saturation; sRAW Specific RAW; TLC Total lung capacity

\section{DISCUSSION}

Our study aimed to characterize lung function in patients with IPF on initial diagnosis. We report the results of patients diagnosised with IPF based on currently accepted criteria (18) referred to a tertiary care centre in Canada. To properly assess lung function in IPF, we excluded subjects with evident airway obstruction on spirometry, patients with conditions that could affect lung function and patients with emphysema on chest CT because combined pulmonary fibrosis and emphysema may represent a distinct clinical phenotype and affects only a minority of patients with IPF (27).

The main findings of the present study are: one in four patients with IPF had a normal TLC and more than one-half had a normal FVC on initial presentation; regardless of the severity of restriction, as measured by reduction of TLC, the average DLCO/VA remained normal; the $\mathrm{FEV}_{1} / \mathrm{FVC}$ ratio increased with increasing severity of restriction; and age was not associated to the severity of restriction.

More than one-quarter of patients with IPF had a normal TLC $(<95 \%$ percentile) on initial evaluation, while more than one-half had a normal FVC. Furthermore, $40 \%$ of patients with restriction - based on a low TLC - had a normal FVC, while no patients with a low FVC had a normal TLC. The variability of TLC was lower than the variability of FVC in our study subjects. Thus, our results suggest that TLC is a more reliable parameter to identify patients with IPF on initial evaluation; however, this should be confirmed in further studies.

The mean TLC of the total sample was $72 \%$ of predicted, which is similar to most studies that have reported TLC in patients with IPF $(2,7,8,12,14)$ since the initial ATS/ERS guidelines were published (28). The mean FVC in our study (71\%) was similar to several studies that have reported FVC in patients with $\operatorname{IPF}(6,8,10,14,15)$ but higher than the FVC reported by others $(2,9,11,16)$. This is likely explained by tertiary care referral and selection biases in previous studies, and different stages of severity of IPF because patients with moderate and severe disease are more likely to be referred to tertiary care centres. Compared with the study by Collard et al (2) - to our knowledge, the only other study reporting most of the lung function parameters we describe - our patients had a significantly higher $\mathrm{FEV}_{1}$, DLCO and 


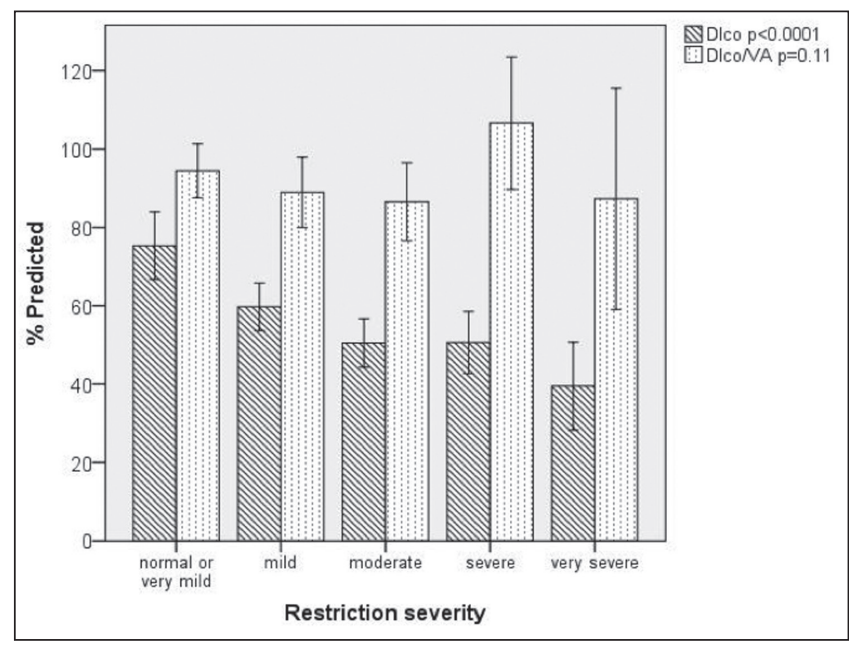

Figure 3) Mean diffusing capacity for carbon monoxide (DLCO) and DLCO/arterial volume (VA) according to the severity of restriction in patients with idiopathic pulmonary fibrosis. Error bars represent 95\% CIs

DLCO/VA, and a lower TLC, which may reflect differences in disease stage or, more likely, the fact that we excluded patients with emphysema. The rationale for excluding these patients was that subjects with combined pulmonary emphysema and fibrosis are a minority among patients with IPF (27) and they could bias the lung function results of most IPF patients.

At presentation, most of our patients had symptoms attributable to IPF; however, one in 16 (6.3\%) were asymptomatic and their diagnosis of IPF was suspected on incidental findings on chest CT during a hospital admission and confirmed with lung biopsy. Previously, Rosas et al (29) identified 22\% (31 of 143) of subjects with asymptomatic IPF among family members with familial IPF; however, the proportion of asymptomatic patients in nonfamilial IPF is not clear.

Because there is no currently accepted classification for severity for restrictive lung diseases, we categorized the severity of restriction based on percentiles (75th, 50th, 25th and 10th). Interestingly, these percentiles coincided with the arbitrary percent predicted cut-offs the ATS/ERS recommend to assess severity of obstruction (26).

It was interesting that age was not associated with severity of restriction in IPF in our patients, suggesting that IPF is a heterogeneous disease that encompasses subgroups of patients with different patterns of severity on initial presentation and, potentially, with different pathophysiology and prognosis. Alternatively, it may be that younger patients perceive symptoms earlier than older patients.

As expected, the DLCO decreased as the severity of restriction increased; however, the correlation between DLCO and TLC in our IPF patients was low $\left(\mathrm{R}^{2}=0.29 ; \mathrm{P}<0.001\right)$, suggesting that the lung recoil and gas exchange abnormalities do not necessarily progress in parallel.

On the other hand, for all degrees of restriction, the mean DLCO/VA remained within normal limits, suggesting that the low DLCO in IPF patients is primarily explained by an abnormal distribution of ventilation, because when corrected by tracer gas measuring alveolar volume, the DLCO is normalized. The fact that DLCO, but not DLCO/VA, declines with the severity of restriction supports the current recommendations to use DLCO over DLCO/VA when interpreting PFTs (26).

Whereas the mean $\mathrm{FEV}_{1}$ declined with progressive restriction, the mean $\mathrm{FEV}_{1} / \mathrm{FVC}$ ratio increased significantly, being highest in patients with the most severe degrees of restriction. This is likely explained by the progressive increase in elastic recoil that occurs with worsening pulmonary fibrosis, which in turn increases the volume-adjusted flows (30).

Clinically significant low $\mathrm{SaO}_{2}(<90 \%)$ was observed only in patients with very severe restriction (TLC $<50 \%)$; with the exception of

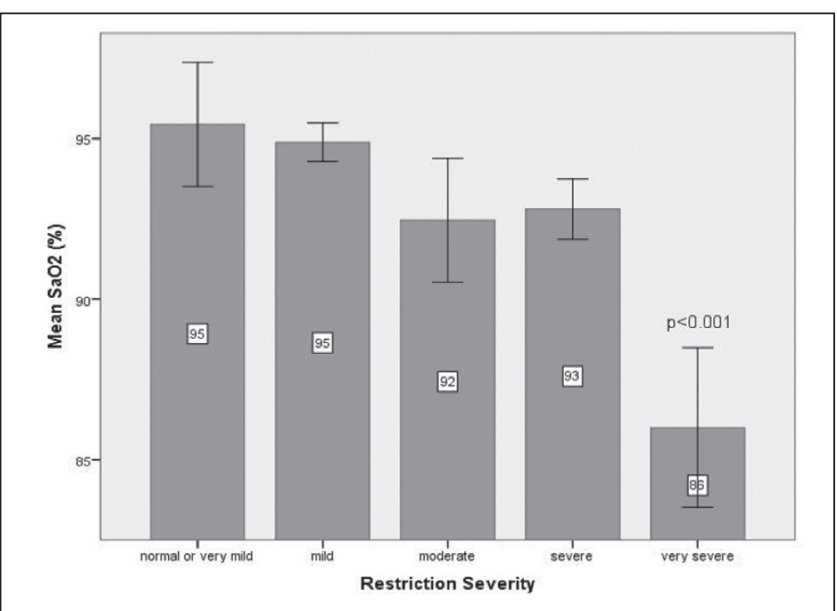

Figure 4) Oxygen saturation ( $\left.\mathrm{SaO}_{2}\right)$ according to the severity of restriction in patients with idiopathic pulmonary fibrosis. The only significant difference in $\mathrm{SaO}_{2}$ was in the very severe restriction group compared with other degrees of restriction $(P<0.001)$. Error bars represent $95 \%$ CIs

one patient with low $\mathrm{SaO}_{2}$ in the group with moderate restriction, all patients with mild, moderate and severe restriction had $\mathrm{SaO}_{2} \geq 90 \%$. Thus, clinicians should expect IPF patients with moderate and even severe restriction to have normal $\mathrm{SaO}_{2}$. On the other hand, if confirmed by future studies, significantly low $\mathrm{SaO}_{2}(<90 \%)$ could help in identifying patients with very severe IPF.

\section{Limitations}

In retrospective studies, missing information is not uncommon, and our study lacked information regarding ABGs for almost one-half of our patients. However, with the exception of missing information on DLCO and DLCO/VA in 11 (12\%) patients, information regarding the other lung function parameters was complete for all of our study patients. Patients with unavailable DLCO data had, on average, more severe restriction (mean TLC 60\%) compared with those with available DLCO (mean TLC 72\%; P<0.05); thus, most patients with missing DLCO results were likely unable to perform the DLCO manoeuvres due to the severity of their disease. Patients with low $\mathrm{SaO}_{2}$ on pulse oximetry were more likely to have ABGs performed; thus, the ABG results reported in our study may not apply to all individuals with IPF on initial evaluation.

Another limitation of our study was the small number of patients with IPF in the 'severe' and 'very severe' categories of restriction (Table 3); thus, the results found on IPF patients with severe and very severe restriction on initial diagnosis should be confirmed in larger studies.

Although our study provides more comprehensive information than previous studies investigating lung function abnormalities in patients with IPF at initial evaluation, no inferences can be made about the prognosis of such patients.

Finally, because our study was not strictly population based, the lung function reported may not accurately reflect that of the general population. However, because universal health care in Canada permits timely access to medical care for all patients, our study approximates a population-based analysis. Thus, our results most likely represent the lung function of most patients with IPF on their initial presentation to a clinician or found incidentally on chest imaging.

\section{CONCLUSION}

We found that one in four patients with IPF had normal TLC and more than one-half had normal FVC on initial evaluation, and that as severity of the restriction increased $\mathrm{FEV}_{1} / \mathrm{FVC}$ increased, DLCO decreased but DLCO/VA remained normal. Also, age was not associated with severity of restriction. Hence, our study provides new knowledge with regard to the physiological abnormalities of IPF at initial presentation that could have important clinical and prognostic implications. 
AUTHOR CONTRIBUTIONS: Arturo Cortes-Telles: conception, research design, obtaining and building the database, analysis and interpretation of data, drafting parts of the manuscript as well as revising it for important intellectual content, and final approval of the manuscript before submission. Lutz Forkert: analysis and interpretation of data, drafting parts of the manuscript as well as revising it critically for important intellectual content and final approval of the manuscript before submission. Denis E O'Donnell: analysis of data, drafting parts of the manuscript as well as revising it critically for important intellectual content and by final approval of the manuscript before submission. Onofre Morán-Mendoza: conception, research design, analysis and interpretation of data, as well as drafting parts of the manuscript, revising it critically for important intellectual content, and final approval before submission and as the guarantor of the article. The authors are indebted to Mr Rod Albrough, Decision Support Analyst at KGH, for providing the data for the study subjects from the KGH database. The authors thank Mrs Geraldine MacDonald for reviewing the manuscript.

\section{REFERENCES}

1. American Thoracic Society/European Respiratory Society International Multidisciplinary Consensus Classification of the idiopathic interstitial pneumonias. Am J Respir Crit Care Med 2002;165:277-304.

2. Collard HR, King TE Jr, Bartelson BB, et al. Changes in clinical and physiologic variables predict survival in idiopathic pulmonary fibrosis. Am J Respir Crit Care Med 2003;168:538-42.

3. Gay SE, Kazerooni EA, Toews GB, et al. Idiopathic pulmonary fibrosis: Predicting response to therapy and survival. Am J Respir Crit Care Med 1998;157(4 Pt 1):1063-72.

4. Ley B, Collard HR, King TE Jr. Clinical course and prediction of survival in idiopathic pulmonary fibrosis. Am J Respir Crit Care Med 2011;183:431-40.

5. Erbes R, Schaberg T, Loddenkemper R. Lung function tests in patients with idiopathic pulmonary fibrosis. Are they helpful for predicting outcome? Chest 1997;111:51-7.

6. Zappala CJ, Latsi PI, Nicholson AG, et al. Marginal decline in forced vital capacity is associated with a poor outcome in idiopathic pulmonary fibrosis. Eur Respir J 2010;35:830-6.

7. Flaherty KR, Mumford JA, Murray S, et al. Prognostic implications of physiologic and radiographic changes in idiopathic interstitial pneumonia. Am J Respir Crit Care Med 2003;168:543-8.

8. Jegal Y, Kim DS, Shim TS, et al. Physiology is a stronger predictor of survival than pathology in fibrotic interstitial pneumonia. Am J Respir Crit Care Med 2005;171:639-44.

9. Daniels CE, Lasky JA, Limper AH, Mieras K, Gabor E, Schroeder DR. Imatinib treatment for idiopathic pulmonary fibrosis: Randomized placebo-controlled trial results. Am J Respir Crit Care Med 2010;181:604-1.

10. King TE Jr, Behr J, Brown KK, et al. BUILD-1: A randomized placebo-controlled trial of bosentan in idiopathic pulmonary fibrosis. Am J Respir Crit Care Med 2008;177:75-81.

11. Raghu G, Brown KK, Bradford WZ, et al. A placebo-controlled trial of interferon gamma-1b in patients with idiopathic pulmonary fibrosis. N Engl J Med 2004;350:125-33.
12. Azuma A, Nukiwa T, Tsuboi E, et al. Double-blind, placebocontrolled trial of pirfenidone in patients with idiopathic pulmonary fibrosis. Am J Respir Crit Care Med 2005;171:1040-7.

13. Noble PW, Albera C, Bradford WZ, et al. Pirfenidone in patients with idiopathic pulmonary fibrosis (CAPACITY): Two randomised trials. Lancet 2011;377:1760-9.

14. Mogulkoc N, Brutsche MH, Bishop PW, Greaves SM, Horrocks AW, Egan JJ. Pulmonary function in idiopathic pulmonary fibrosis and referral for lung transplantation. Am J Respir Crit Care Med 2001;164:103-8.

15. Latsi PI, du Bois RM, Nicholson AG, et al. Fibrotic idiopathic interstitial pneumonia: The prognostic value of longitudinal functional trends. Am J Respir Crit Care Med 2003;168:531-7.

16. Flaherty KR, Andrei AC, Murray S, et al. Idiopathic pulmonary fibrosis: Prognostic value of changes in physiology and six-minutewalk test. Am J Respir Crit Care Med 2006;174:803-9.

17. Schmidt SL, Nambiar AM, Tayob N, et al. Pulmonary function measures predict mortality differently in IPF versus combined pulmonary fibrosis and emphysema. Eur Respir J 2011;38:176-83.

18. Raghu G, Collard HR, Egan JJ, et al. An official ATS/ERS/JRS/ ALAT statement: Idiopathic pulmonary fibrosis: Evidence-based guidelines for diagnosis and management. Am J Respir Crit Care Med 2011;183:788-824.

19. Macintyre N, Crapo RO, Viegi G, et al. Standardisation of the single-breath determination of carbon monoxide uptake in the lung. Eur Respir J 2005;26:720-35.

20. Miller MR, Hankinson J, Brusasco V, et al. Standardisation of spirometry. Eur Respir J 2005;26:319-38.

21. Wanger J, Clausen JL, Coates A, et al. Standardisation of the measurement of lung volumes. Eur Respir J 2005;26:511-22.

22. Crapo RO, Morris AH, Gardner RM. Reference spirometric values using techniques and equipment that meet ATS recommendations. Am Rev Respir Dis 1981;123:659-64.

23. Goldman HI, Becklake MR. Respiratory function tests; normal values at median altitudes and the prediction of normal results. Am Rev Tuberc 1959;79:457-67.

24. Briscoe WA, Dubois AB. The relationship between airway resistance, airway conductance and lung volume in subjects of different age and body size. J Clin Invest 1958;37:1279-85.

25. Crapo RO, Morris AH. Standardized single breath normal values for carbon monoxide diffusing capacity. Am Rev Respir Dis 1981;123:185-9.

26. Pellegrino R, Viegi G, Brusasco V, et al. Interpretative strategies for lung function tests. Eur Respir J 2005;26:948-68.

27. Ryerson CJ, Hartman T, Elicker BM, et al. Clinical features and outcomes in combined pulmonary fibrosis and emphysema in idiopathic pulmonary fibrosis. Chest 2013;144:234-40.

28. American Thoracic Society. Idiopathic pulmonary fibrosis: Diagnosis and treatment. International consensus statement. American Thoracic Society (ATS, and the European Respiratory Society) (ERS). Am J Respir Crit Care Med 2000;161(2 Pt 1):646-64.

29. Rosas IO, Ren P, Avila NA, et al. Early interstitial lung disease in familial pulmonary fibrosis. Am J Respir Crit Care Med 2007;176:698-705.

30. Nava S, Rubini F. Lung and chest wall mechanics in ventilated patients with end stage idiopathic pulmonary fibrosis. Thorax 1999;54:390-5. 


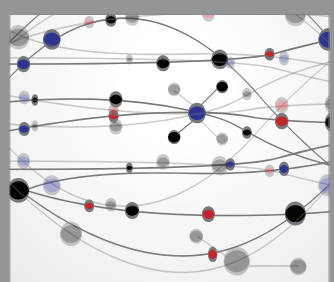

The Scientific World Journal
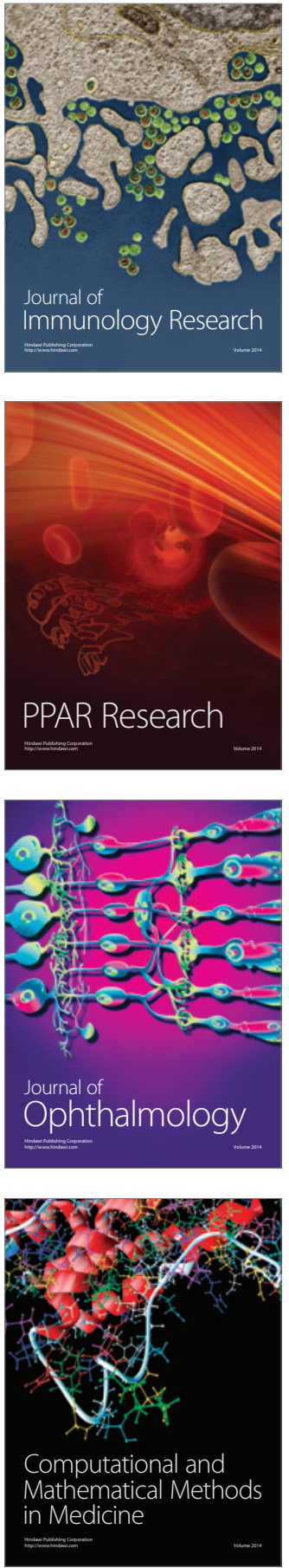

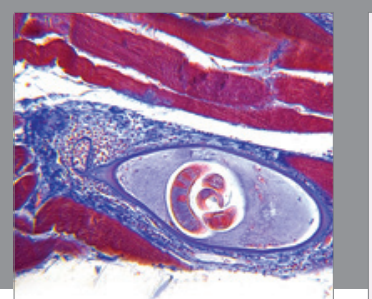

Gastroenterology Research and Practice

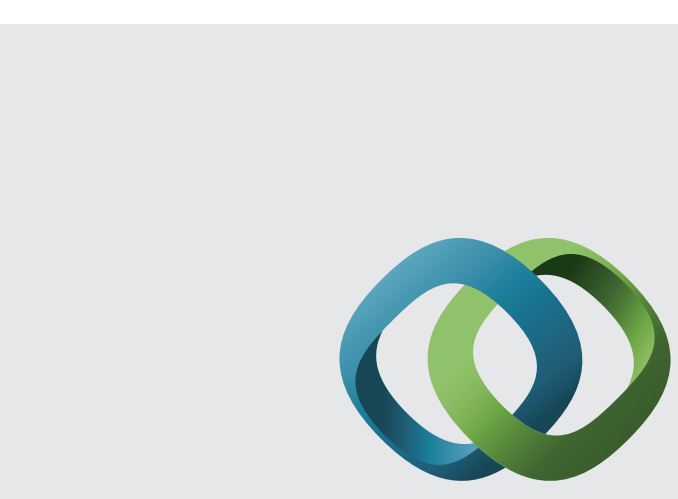

\section{Hindawi}

Submit your manuscripts at

http://www.hindawi.com
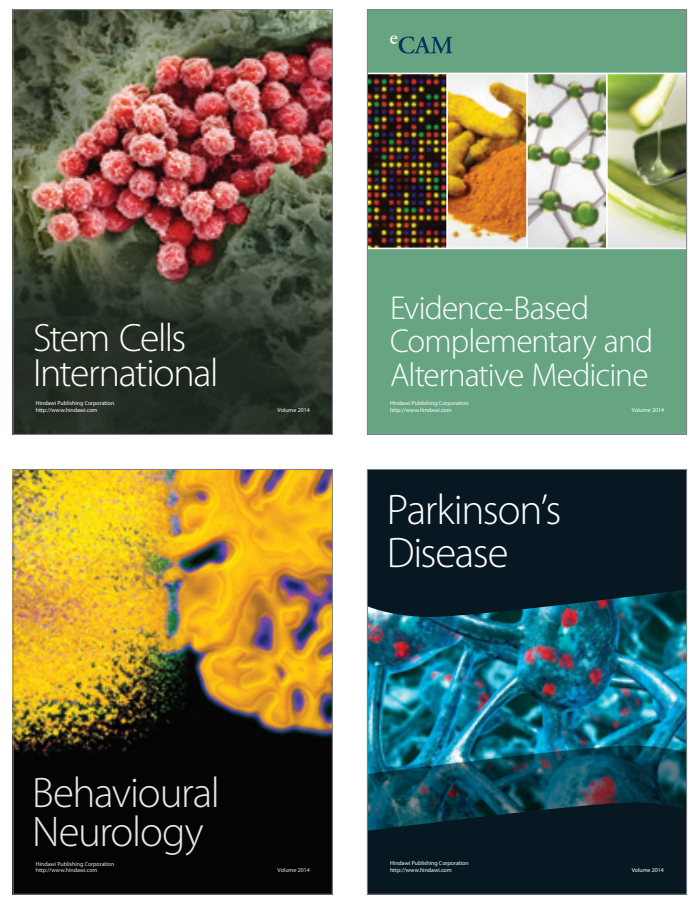
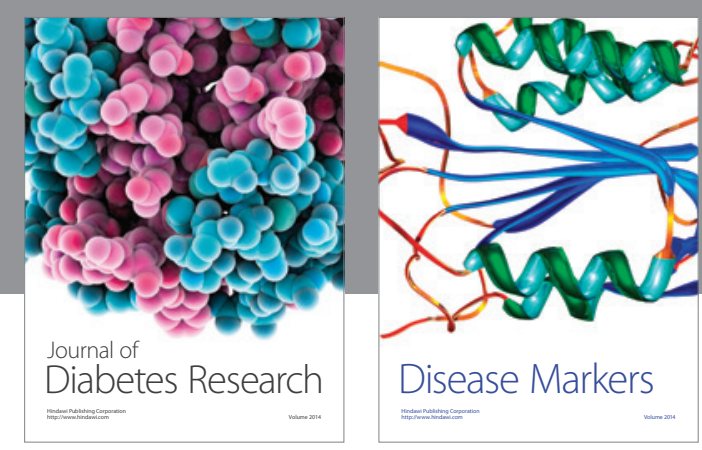

Disease Markers
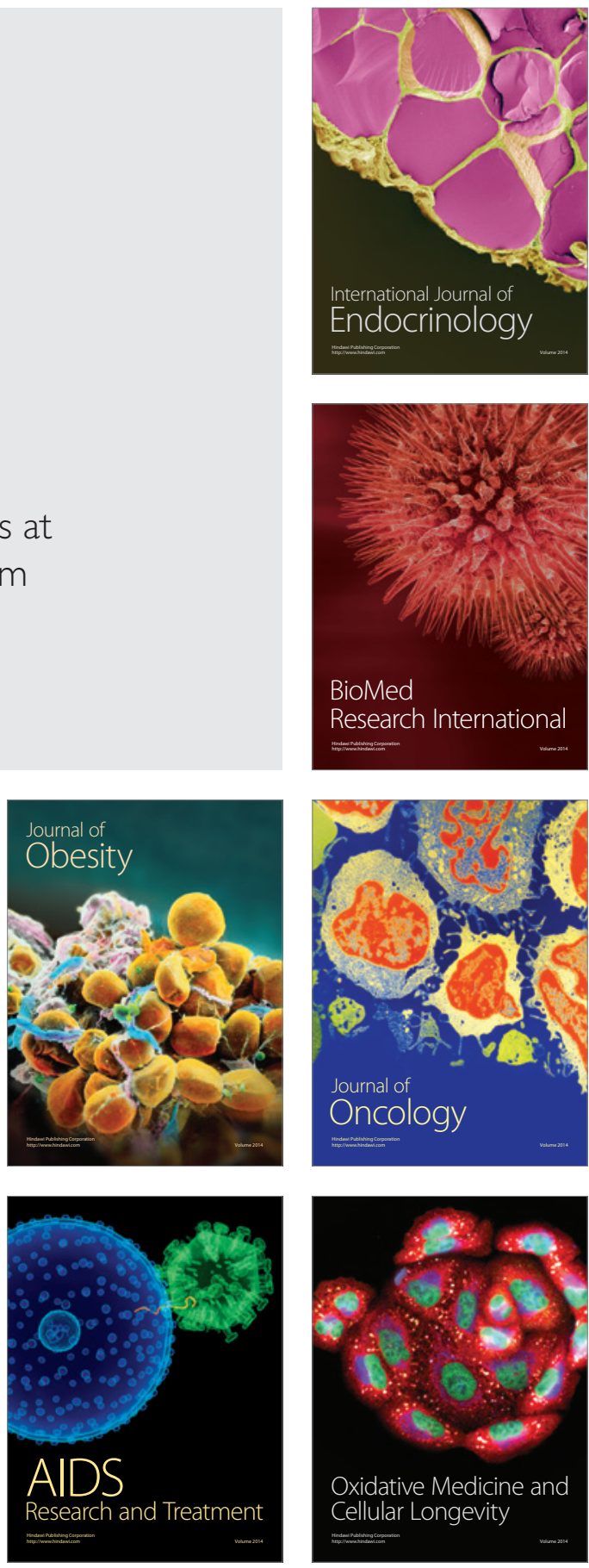